\title{
Physical and Chemical Properties of Banana Fibre Extracted from Commercial Banana Cultivars Grown in Tamilnadu State
}

Preethi P* and Balakrishna Murthy G

Horticultural College and Research Institute, Tamil Nadu Agricultural University, Coimbatore, Tamilnadu, India

\begin{abstract}
Banana is one of the important fruit crop cultivated in tropical parts of the world. Banana farming generates huge quantity of biomass all of which goes as waste and the above ground parts like pseudostem and peduncle are the major source of fibre. Banana fibre can be used as raw material for industry for production of range of products like paper, cardboards, tea bags, currency notes and reinforced as polymer composite in high quality dress materials. Fibre from pseudostem and peduncle of four commercial cultivars of Tamil Nadu viz., Grand Naine, Poovan, Monthan and Nendran were extracted using banana fibre extraction machine. The highest pseudostem and peduncle fibre recovery were obtained from Poovan $(2.71 \%$ and $1.09 \%$, respectively) and the lowest from Grand Naine $(1.07 \%$ and $0.63 \%$, respectively). Cellulose is the major component of the fibre. The highest cellulose content was recorded in Nendran peduncle fibre $(60.27 \%)$ followed by Nendran pseudostem fibre $(59.23 \%)$. The other non- cellulosic substances like hemicellulose, lignin and pectin were high in Monthan pseudostem fibre 1 15.75, 21.56 and $4.08 \%$, respectively). Mechanical properties like tex and fibre diameter decides the fineness. Fine fibres were obtained from pseudostem of Nendran (24.23 tex and $0.119 \mathrm{~mm}$, respectively). The breaking load, breaking extension and tenacity were found to be good in peduncle fibres of Nendran cultivar $(332.33 \mathrm{~g}, 2.01 \%$ and $39.56 \mathrm{~g} / \mathrm{tex}$ ).
\end{abstract}

Keywords: Banana; Pseudostem; Peduncle; Fibre; Physico-chemical properties

\section{Introduction}

Mankind has been strongly dependent on plant fibres for all kind of purposes. In earlier days, natural fibres served a crucial role mitigate the everyday needs in a wide range of uses. But in recent years the arrival of synthetic products are dominating over the natural fibre, due to the low cost. But the synthetic fibres are non degradable and causing serious pollution problems. Banana is one of the earliest and important fruit crops cultivated by man in tropical parts of the world. Banana is distributed in more than 120 countries, over an area of 48 lakh hectares, with an annual production of 99.99 million tons in the year 2011 (Indian Horticulture Database, 2011). Banana farming generated huge quantities of biomass all of which goes as waste due to non availability of suitable technology for its commercial utilization. Normally this biomass is used for animal feed and fuel. Among its multi faced uses like therapeutic, alcohol, starch extraction and other innumerable uses, they are the best source of fibre. India has about 8.3 lakh ha under banana cultivation (Indian Horticulture Database, 2011) producing approximately 51.18 million tons of pseudostem waste per year. This can be profitably used for extracting approximately 3.87 million tons of fibre. Apart from being food-fruit crop, banana plant is versatile with respect to its utilities. Banana fibre from pseudostem is said to be superior and in the mid-19th century, there was quite active banana fibre industries in Jamaica. Species such as Musa textalis are well known for their strong fibre qualities. Wild species like Musa balbisiana var. cola, Musa balbisiana var. andamanica existing in Andaman and Nicobar Islands are used for extracting fibre. In the Philippines, it is woven into a thin, transparent fabric called "agna" which is the principle material in some regions for men's shirts. It is also used for making hand kerchiefs. In Sri Lanka, it is fashioned into soles for expensive shoes and used for floor coverings. Improved processes have made it possible to utilize banana fibre for manufacture of paper, currency, ropes, cordages, gunny bags, handicrafts etc. Starch is manufactured form pseudostem and the juice from the pseudostem can also be used in dyes as it has a property of a permanent stain. Seat pads for benches are made of strips of dried banana pseudostem in Ecuador. Apart from the pseudostem, banana peduncle has also been found to be a good source of cellulose rich fibre. These fibres are used as a composite in polymer matrix [1]. It is estimated that banana peduncle and leaves occupies $20 \%$ of the plant total biomass [2]. Even though peduncle is a rich source of cellulose, research reports available on extraction of fibre from peduncle are scanty. This necessitates the research study on evaluation of elite banana cultivars for extraction of fibre form pseudostem and peduncle of few important commercial cultivars. As banana peduncle are dumped on road side or burnt which causes environmental pollution. This will also surely help in solving the environmental problems.

\section{Review of Literature}

\section{Effect of genomes on yield and quality of fibres}

The genomic status of a variety also has a major role with respect to biomass production. The fibre extractable pseudostem and fibre yield percentage was found to be $46.4 \%$ and $0.53 \%$ of the extractable pseudostem in dessert cultivars and $55.2 \%$ and $0.78 \%$, respectively, in culinary types [3]. Uma et al. [2] studied the fibre yield and quality of six cultivars (Robusta, Poovan, Pachanadan, Karpuravali, Peyan and Saba). The fibre recovery percentage and cellulose content were high in Pachanadan (0.88\% and 57.89\%).

${ }^{*}$ Corresponding author: Preethi P, Horticultural College and Research Institute Tamil Nadu Agricultural University, Coimbatore, Tamilnadu, India, E-mail: pppreethihorti@gmail.com

Received December 13, 2012; Accepted December 15, 2012; Published Apri 15,2013

Citation: Preethi P, Balakrishna Murthy G (2013) Physical and Chemical Properties of Banana Fibre Extracted from Commercial Banana Cultivars Grown in Tamilnadu State. Agrotechnol S11: 008. doi:10.4172/2168-9881.S11-008

Copyright: @ 2013 Preethi P, et al. This is an open-access article distributed unde the terms of the Creative Commons Attribution License, which permits unrestricted use, distribution, and reproduction in any medium, provided the original author and source are credited. 
Citation: Preethi P, Balakrishna Murthy G (2013) Physical and Chemical Properties of Banana Fibre Extracted from Commercial Banana Cultivars Grown in Tamilnadu State. Agrotechnol S11: 008. doi:10.4172/2168-9881.S11-008

Page 2 of 3

\section{Properties of banana fibre}

Bilba et al. [4] determined the chemical composition of banana pseudostem by elemental analysis. The results were as follows, cellulose-31-35\%, hemicellulose-14-17\% and lignin-15-16\%.

Reddy and Yang [5] analysed the production processes, structure, properties and suitability of biofibres for various industrial applications. They studied the properties of banana fibre, pineapple leaf fibre, coir, wheat straw, barley straw and rice straw and resulted that pineapple and banana fibers have higher cellulose content $70-82 \%$ and $60-65 \%$, respectively. The banana fibre showed the diameter of $80-250 \mu \mathrm{m}$ with the elongation percentage of 1.0-3.5. Kiruthika and Veluraja [6] studied the physical properties of banana pseudostem fibre. The varieties selected by them were Red Banana, Nendra, Rasthaly, Morris and Poovan. They found that the tensile strength of Red Banana fibres was high (525 MPa) followed by Nendra (456 MPa), Rasthaly (346 MPa), Morris (252 MPa) and Poovan (175 MPa).

\section{Materials and Methods}

\section{Extraction of fibre from pseudostem and peduncle of different banana cultivars}

The pseudostem and peduncle of following banana cultivars viz., Grand Naine, Poovan, Nendhran and Monthan were collected and stripped and used for fibre extraction. The stripped ribbons of pseudostem are basically known as Tuxies [7]. Fibre was extracted from the pseudostem of different cultivars using semi-automatic machine, developed by KVK, C.T.R.I (ICAR), Rajamandry, Inida.

\section{Observations recorded}

Pseudostem weight, fibre extractable pseudostem: The whole plant was uprooted after bunch harvesting and the pseudostem was separated and weighed. These pseudostems were further divided into fibre-extractable pseudostem and fibre-non-extractable pseudostem. Starting from the outermost layers, up to 10 layers was taken as fibre extractable pseudostem [2]. The weighed fibre extractable pseudostem was cut into $1 \mathrm{~m}$ pieces and placed for fibre extraction. Peduncle were divided into stripes and placed in the fibre extraction.

Fibre yield and recovery percentage: The fibre yield was weighed and the recovery percentage were calculated as follows,

$$
\text { Recovery percentage }=\frac{\text { Weight of fibre }(\mathrm{g})}{\text { Weight of fibre extractable pseudostem or peduncle }(\mathrm{g})} \times 100
$$

Mechanical properties-measurement of single fibre: Tensile tests were carried out in Universal Instron Tester (Model 3345) in TIFAC core Dept, Kumaraguru College of Technology, Saravanampatty, Coimbatore. The load developed and corresponding extension at the point of rupture were recorded as the breaking load and breaking extension, respectively, using dedicated computer software (Blue hill). Tex-Tex is a measure of linear density of fibres. Breaking load-The maximum force applied to the fibre carried to rupture; applied force is generally expressed as gram-force (gf). Breaking extension-The extension of fibre to the length of the fibre prior to stretching, expressed at percentage. Tenacity-The tenacity was calculated from the breaking force and the linear density of the unstrained specimen, commonly expressed as gram-force per tex (gf/tex) [8]. Diameter-The diameter of the fibre was calculated by using the ocular meter (Manufactured by Erma, Tokyo, Japan).

20 lines of ocular lens $=30$ stages

1 ocular $=1.5$ stages

\section{$1.5 \times 0.01 \mathrm{~mm}=0.015 \mathrm{~mm}(1$ line $=0.01 \mathrm{~mm})$}

Chemical properties: Chemical properties ie., cellulose, hemicellulose and pectin were estimated according to the method suggested by Sadasivam and Manickam [9]. Lignin was estimated of Thimmaiah's method [10]. The chemical properties were expressed in per cent.

\section{Results}

Fibre yield from pseudostem and peduncle of commercial cultivars of banana

The data (Figure 1) showed that the pseudostem, peduncle weight and fibre yield differs significantly among the cultivars. The highest fibre recovery per cent was obtained from pseudostem of Poovan $(2.71 \%)$ followed by pseudostem of Nendran (2.30\%). The lowest was recorded in peduncle of Nendran $(0.283 \%)$.

\section{Mechanical properties of fibre}

Cultivar influence on physical properties of pseudostem and peduncle fibres: Tex and Diameter decides the fineness of the fibres. Tex is a measurement of linear density of fibres, decides the fineness of fibre. Significant differences were observed in the Tex of pseudostem and peduncle fibres (Table 1). Fine fibres were obtained from pseudostem of Poovan (24.23). The fibre extracted from peduncle of Grand Naine was comparatively coarse in nature (8.4). According to diameter, pseudostem and peduncle fibres of Nendran $(0.119 \mathrm{~mm} \& 0.129 \mathrm{~mm})$. Breaking load (g), breaking extension (\%) and tenacity (g/tex) decides the strength of the fibre. The table 1 showed highest breaking load and breaking extension were observed in Nendran peduncle fibres (332.33 $\mathrm{g} \& 2.01 \%)$ followed by Nendran pseudostem fibres (327.33 g 1.67\%). Tenacity was found to be high in Nendran peduncle fibres $(22.92 \mathrm{~g} / \mathrm{tex})$ followed by Monthan peduncle fibres ( $15.36 \mathrm{~g} / \mathrm{tex})$.

\section{Chemical properties of fibre}

Cultivar influence on chemical properties of pseudostem and peduncle fibres: In the table 2 chemical components viz., cellulose, hemicelluloses, pectin and lignin content of fibres differed significantly among the pseudostem and peduncle of different banana cultivars. Cellulose has a major role in deciding the quality of the fibres. The highest cellulose content was observed in Nendran peduncle fibre (60.41\%), Nendran pseudostem fibre (59.22\%). The lowest cellulose content was observed in Grand Naine pseudostem fibre (48.19\%) and Grand Naine peduncle fibre (48.31\%) which was on par with each other. The maximum hemi-cellulose content was observed in Grand

\section{fibre recovery per cent}

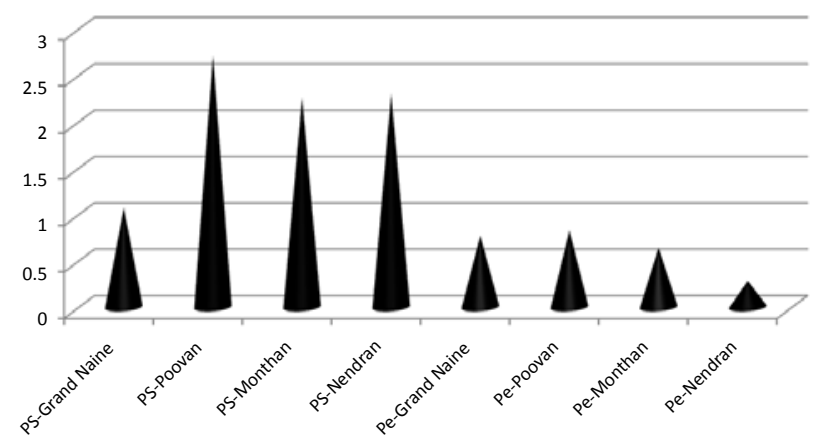

Figure 1: Fibre recovery per cent of different banana cultivars. 
Citation: Preethi P, Balakrishna Murthy G (2013) Physical and Chemical Properties of Banana Fibre Extracted from Commercial Banana Cultivars Grown in Tamilnadu State. Agrotechnol S11: 008. doi:10.4172/2168-9881.S11-008

Page 3 of 3

\begin{tabular}{|l|c|c|c|c|c|c|}
\hline $\begin{array}{l}\text { Parts used } \\
\text { for fibre } \\
\text { extraction }\end{array}$ & Cultivars & Tex & $\begin{array}{c}\text { Diameter } \\
\mathbf{( m m )}\end{array}$ & $\begin{array}{l}\text { Breaking } \\
\text { load } \mathbf{( g )}\end{array}$ & $\begin{array}{c}\text { Breaking } \\
\text { extension } \\
\mathbf{( \% )}\end{array}$ & $\begin{array}{c}\text { Tenacity } \\
\mathbf{( g / t e x )}\end{array}$ \\
\hline Pseudostem & Grand Naine & 13.33 & 0.225 & 100.20 & 1.02 & 7.52 \\
\cline { 2 - 7 } & Poovan & 24.00 & 0.142 & 186.20 & 1.23 & 7.76 \\
\cline { 2 - 7 } & Monthan & 22.00 & 0.170 & 114.97 & 1.34 & 5.23 \\
\cline { 2 - 7 } & Nendran & 24.23 & 0.119 & 327.37 & 1.67 & 13.51 \\
\hline \multirow{3}{*}{ Peduncle } & Grand Naine & 8.4 & 0.188 & 109.80 & 0.98 & 13.07 \\
\cline { 2 - 7 } & Poovan & 11.23 & 0.146 & 171.43 & 1.13 & 15.27 \\
\cline { 2 - 7 } & Monthan & 10.67 & 0.142 & 163.93 & 1.45 & 15.36 \\
\cline { 2 - 7 } & Nendran & 14.50 & 0.129 & 332.33 & 2.01 & 22.92 \\
\hline & Mean & $\mathbf{1 6 . 0 4 5}$ & $\mathbf{0 . 1 5 7}$ & $\mathbf{1 8 8 . 2 7}$ & $\mathbf{1 . 3 5}$ & $\mathbf{1 2 . 5 8}$ \\
\cline { 2 - 7 } & CD (p=0.05) & $\mathbf{2 . 3 1}$ & $\mathbf{0 . 0 2 2}$ & $\mathbf{2 8 . 7 0}$ & $\mathbf{0 . 1 9 3}$ & $\mathbf{1 . 8 9}$ \\
\hline
\end{tabular}

Table 1: Physical properties of pseudostem and peduncle fibre extracted from different banana cultivars.

\begin{tabular}{|l|c|c|c|c|c|}
\hline $\begin{array}{l}\text { Parts used for } \\
\text { fibre extraction }\end{array}$ & Cultivars & $\begin{array}{c}\text { Cellulose } \\
\mathbf{( \% )}\end{array}$ & $\begin{array}{c}\text { Hemicellulose } \\
\mathbf{( \% )}\end{array}$ & $\begin{array}{c}\text { Lignin } \\
\mathbf{( \% )}\end{array}$ & $\begin{array}{c}\text { Pectin } \\
\mathbf{( \% )}\end{array}$ \\
\hline Pseudostem & Grand Naine & 48.19 & 15.91 & 19.17 & 3.46 \\
\cline { 2 - 6 } & Poovan & 57.57 & 12.65 & 16.71 & 2.82 \\
\cline { 2 - 6 } & Monthan & 48.55 & 15.75 & 21.56 & 4.08 \\
\cline { 2 - 6 } & Nendran & 59.22 & 12.09 & 14.39 & 2.68 \\
\hline \multirow{3}{*}{ Peduncle } & Grand Naine & 48.31 & 13.99 & 19.87 & 3.25 \\
\cline { 2 - 6 } & Poovan & 56.24 & 14.89 & 19.17 & 2.62 \\
\cline { 2 - 6 } & Monthan & 49.65 & 15.75 & 20.66 & 3.87 \\
\cline { 2 - 6 } & Nendran & 60.41 & 10.20 & 17.56 & 2.06 \\
\hline & Mean & $\mathbf{5 3 . 5 2}$ & $\mathbf{1 3 . 9 0}$ & $\mathbf{1 8 . 6 4}$ & $\mathbf{3 . 1}$ \\
\cline { 2 - 6 } & CD (p=0.05) & $\mathbf{7 . 4 4}$ & $\mathbf{1 . 9 4}$ & $\mathbf{2 . 5 9}$ & $\mathbf{0 . 4 4 0}$ \\
\hline
\end{tabular}

Table 2: Chemical properties of pseudostem and peduncle fibre extracted from different banana cultivars.

Naine pseudostem fibre (15.91\%), pseudostem and peduncle fibres of Monthan (15.75\%). The delignification process decreases the lignin content accompanied by a small decrease in elongation at break. As lignin content was decreased below $0.78 \%$, tenacity continued to decrease. Highest lignin content was observed in pseudostem and peduncle fibre of Monthan cultivar (21.56\% and 20.66\%) and the lowest was observed in Nendran pseudostem fibre (14.39\%). Pectin was found to be high in pseudostem and peduncle fibres of Monthan (4.08 and $3.87 \%)$ and low in peduncle fibre of Nendran (2.06\%).

\section{Discussion}

Pseudostem and peduncle weight and fibre yield: The collected pseudostem form different cultivars of banana showed a significant difference in weight. Grand Naine (AAA) showed the maximum pseudostem weight among the studied cultivars. The peduncle weight was high in Poovan (AAB). Genome A tends to produce greater and bulky pseudostem. This was also reflecting in fibre yield and recovery percentage. Top 8 layers had been chosen for fibre extraction, since the outer sheaths were exposed to extreme weather condition, more prone to insect attack. According to fibre recovery percentage the genomes $\mathrm{A}$ and $\mathrm{B}$ had no influence. Because, the fibre recovery percentage was high in Nendran (AAB) and Grand Naine (AAA) was observed as poor source of fibre. The relative combinations of the $A$ and $B$ genomes received from Musa acuminata and Musa balbisiana, respectively. In general B genome responses to produce strong and bulky plants with greater genome. Therefore, plants with a greater proportion of the $\mathrm{B}$ genome produce more biomass than other triploids. This finding was supported by Uma et al. [2], as all the cultivar with B genome had a higher biomass owing to precocity and general robustness greatly to plant biomass production. But according to them, the genomic constitution had less influence on the fibre extractable pseudostem. Among the genomic constituents $\mathrm{AAA}, \mathrm{AAB}, \mathrm{ABB}$ and $\mathrm{AB}$, cultivars belonging to AAA exhibited a higher percentage of pseudostem weight and fibre extractable pseudostem. According to the results of Sivashankar et al. [11] the genomic constituent had no influence on pseudostem weight, fibre extractable pseudostem weight and fibre yield.

\section{References}

1. Ratnaprasad AV, Rao KM, Nagasrinivasulu G (2009) Mechanical properties of banana empty fruit bunch fibre reinforced polyester composites. Indian journal of fiber and textile research 34: 162-167.

2. Uma S, Kalpana S, Sathiyamoorthy S, Kumar V (2005) Evaluation of commercial cultivars of banana (Musa spp.) for their suitability for the fibre industry. Plant Genetic Resources Newsletter 142: 29-35.

3. Uma S, Kalpana S, Sathiyamoorthy S (2003) In: Banana Fibre, National Research Centre for banana: 6-18.

4. Bilba K, Arsene MA, Ouensanga A (2007) Study of banana and coconut fibers: Botanical composition, thermal degradation and textural observations. Bioresource Technology 98: 58-68.

5. Reddy N, Yang Y (2005) Biofibers from agricultural byproducts for industrial applications, Trends in Biotechnology 23: 22-27.

6. Kiruthika AV, Veluraja K (2009) Experimental Studies on the Physico-chemical Properties of Banana Fibre from Various Varieties. Fibers and Polymers 10: 193-199.

7. Lewin M, Sello SB (1984) Natural Fibres. In: Handbook of Fibre Science and technology, CRC Press, Boca Raton, 5-14.

8. CIRCOT (1999) Tensile Properties of Fibres, An Insight Into Ligno-cellulosic Fibres- Structure and Properties, Technical bulletin Published by the central Institute for Research on cotton Technology, Matunga, India 11-24.

9. Sadasivam S, Manickam A (1996) In: Biochemical Methods $2^{\text {nd }}$ edition. (Eds.) New Age International (P) Limited Publishers, New Delhi, 13-19.

10. Thimmaiah SK (1999) In: Standard methods of Biochemical analysis. (Eds.) Kalyani Publishers, New Delhi, 287-310.

11. Sivashankar S, Nachane RP, Kalpana S (2006) Composition and properties of fibre extracted from pseudostem of banana (Musa sp). Journal of Horticultural Science 1: 95-98. 